\title{
Transgressões e estigmas nos modelos de representação autobiográfica
}

\author{
Janaina Leite ${ }^{1}$
}

\section{Resumo}

A partir do conceito de formação - ou Bildung - surgido na modernidade é que se forma o principal modelo de representação autobiográfica que perdura até os dias de hoje. Encontramos nesse modelo a origem da associação da expressão autobiográfica com um certo caráter "terapêutico" e exemplar. O artigo pretende demonstrar o que justifica tal associação, mas também desconstruir o que paira como um estigma em relação a obras autobiográficas, ao tratar das rupturas do modelo narrativo da Bildung a partir das vanguardas nos anos 1970.

Palavras-chave: Autobiografia; Bildung; Arte Contemporânea.

\section{Abstract}

From the concept of training - or Bildung - emerged in modernity is that forms the main autobiographical representation model that endures to this day. We found that model the origin of the association of expression with a certain autobiographical character "therapeutic" and exemplary. The article argues that justifies such an association, but also deconstruct hovering like a stigma towards autobiographical works, when dealing with ruptures narrative model of Bildung from the vanguards in the 1970s.

Keywords: Autobiography; Bildung; Contemporary Art.

Tomando o problema da associação de obras autobiográficas como certa "necessidade terapêutica" - o que leva muitas vezes a sua desvalorização - podemos pensar que, sob certo aspecto, o autobiográfico e a história de sua consolidação enquanto gênero contribuíram para que se formasse esse senso comum. O "gênero" autobiográfico se institui enquanto tal no século XVIII e tem seu marco principal nas Confissões de Jean-Jacques Rousseau (1712-1778). É claro que essa não é primeira obra escrita em primeira pessoa. Das histórias dos santos e reis aos primeiros ensaios pessoais, como temos em Montaigne no século XVI, emergiram diferentes experiências e modelos a partir dos quais o "eu" se enuncia. No entanto, o modelo autobiográfico surgido com Rousseau parte de uma consciência de si que não era possível em épocas anteriores. Ela em nada se compara, por exemplo, à consciência possível do

\footnotetext{
1 Janaina Leite é atriz, diretora e integrante do grupo XIX de teatro. Iniciou sua pesquisa sobre documentário e autobiografia no teatro em 2008 com a criação do espetáculo "Festa de separação: um documentário cênico" e desenvolve mestrado no programa de Pós-Graduação em Artes Cênicas da Escola de Comunicação e Artes da USP com apoio da FAPESP.
} 
homem medieval na qual a ideia de "eu" estava ancorada em uma função social clara e espelhada num modelo inequívoco, vindo ora da igreja, ora do rei. Por essa razão, as hagiografias (histórias dos santos) ou as crônicas reais (histórias de reis) não eram a expressão de uma história e experiência individuais, mas eram exemplos que correspondiam absolutamente a uma função determinada e esperada socialmente.

Diferente é a possibilidade de representação do "eu" que emerge no século XVIII. Ao invés de um modelo absoluto, a Idade Moderna é marcada pela emergência de um modo de construção biográfica pela qual o indivíduo "tende a dar-se a si mesmo sua própria lei de constituição e a encontrar na sua própria experiência os recursos de sua individuação" ${ }^{2}$ É a partir desses pressupostos que nasce o modelo narrativo de representação autobiográfica que perdura até hoje, apesar da revolução cultural da pós-modernidade.

E que "modelo" é esse, tão sólido a ponto de se configurar enquanto gênero e de resistir às intensas transformações culturais e sociais do nosso tempo atual? Trata-se das narrativas de formação ou, como consolidou-se na Alemanha com os principais teóricos dessa modalidade como Goethe e Schiller, a Bildung. Segundo Delory-Momberger, o conceito de Bildung designa "o movimento de formação de si, pelo qual o ser único que constitui todo homem faz com que advenham as disposições que são suas e participa, assim, à realização do humano como valor universal"3. Em outras palavras, trata-se do relato retrospectivo de como alguém se torna o que se é, dentro de uma perspectiva finalista, ou seja, de que há um caminho a ser percorrido para se alcançar um lugar de sabedoria e harmonia dentro dos valores compartilhados pela sociedade. Existiria, portanto, segundo esse modelo, uma forma adequada para a realização de si e essas narrativas revelariam as etapas dessa evolução, sendo o relato da trajetória sempre orientado pelo fim a que se chegou. Os romances de formação ou a Bildungsroman serão o grande exemplo na literatura desse modo de representação biográfica que nasce na modernidade.

Do ponto de vista histórico, tal possibilidade de representação do eu, se deve a dois fatores determinantes: a consolidação do modo capitalista de produção e a configuração da organização burguesa de vida. Estamos falando de novas estruturas de poder e de um novo modo de produção. E falamos, também, de novas relações entre

2 DELORY-MOMBERGER, 2009, p.100.

3 DELORY-MOMBERGER, 2009, p.101. 
indivíduo e sociedade e das formas por meio das quais o indivíduo representa não só essa relação, mas a própria consciência de si neste novo quadro social.

\begin{abstract}
A concepção de indivíduo que toma forma com a sociedade burguesa é a de um ser responsável e autônomo, que se faz por si mesmo; que tem que fazer seu caminho na vida e que deve encontrar seu lugar na sociedade. Essa representação de um devir individual portador de trans-formação integra as noções de concorrência, de risco, de luta pela vida, mas também de amostragem de alternativas, de escolha. ${ }^{4}$
\end{abstract}

Com vistas à consolidação deste modo de vida emergente é que essas narrativas da Bildungsroman vão, consciente ou inconscientemente, trabalhar.

Para o homem de hoje, que tem seus valores principais fundados na modernidade, ainda perdura esse modelo de representação biográfica. Não à toa, grande parte das autobiografias corresponde exatamente a essa teleologia: o que acompanhamos é a passagem de um estágio a outro em que, depois de erros, desafios, desilusões, finalmente, após a superação, atinge-se uma virada do conhecimento na qual se torna possível a verdadeira realização de si.

Todo este preâmbulo nos deixa às portas da crise instaurada nos anos 1970 e que vai abalar o modelo descrito até aqui. Trata-se de um período marcado por uma intensa transformação sociocultural que vai engendrar formas inéditas de autorrepresentação. Ainda que o modelo da Bildung continue imperando na literatura de "autoajuda" ou nas biografias de celebridades, algo, na experiência contemporânea, não consegue mais se fazer reconhecer por esta forma de contar a vida.

Já não é possível localizar a gênese da história de um indivíduo e organizá-la em função de um fim único ao qual, desde o início, ele devesse se adequar. Os anos 1970 ou a chamada "pós-modernidade" caracterizam-se, justamente, por essa perda de unidade da experiência que garantia a base para o modelo de narração de uma trajetória de vida orientada para um fim claro. "A atividade social do indivíduo pós-moderno é conduzida por relações temporárias e reversíveis de inclusão em subsistemas, aos quais ele acede conforme é conduzido por setores de sua vida"5. E cada um desses subsistemas cria suas plataformas de interação, presenciais e/ou virtuais, nas quais o indivíduo se autorrepresenta a partir de escolhas múltiplas, transitórias, que ele manipula de acordo com os códigos e expectativas de cada subsistema. Dentro de nossa problemática, então, das possibilidades de representação de si que emergem em cada

4 DELORY-MOMBERGER, 2009, p.103.

5 Idem, p.105. 
contexto sócio-histórico, o que temos, como coloca Delory-Momberger, é uma proliferação de modelos biográficos já que "as antigas programações biográficas perdem sua centralidade e sua rigidez e os indivíduos são levados a "escolher" entre opções biográficas múltiplas e a forjar, por si próprios, o desenrolar de suas vidas"6. Segundo a autora, com isso os indivíduos ganham "uma competência reflexiva que os conduz a pensar o desenrolar de suas vidas no campo da tensão de suas experiências e figurações biográficas e nos contextos sociais nos quais eles atuam." É nesse sentido que a arte contemporânea parece estar formulando respostas às problemáticas da autorrepresentação neste novo contexto. De fato, os anos 1970 nas artes são marcados por um forte vanguardismo que vai contestar os modelos representacionais vigentes e reivindicar um forte experimentalismo. Nas artes plásticas, na performance art, e também nas artes cênicas dentro da chamada cena "pós-dramática" ou "performativa" explodem as experiências radicalmente e afirmativamente autobiográficas. Vários são os exemplos de artistas e obras que trazem para dentro de seus projetos novas concepções do que seja o gesto autorrepresentacional, o trabalho sobre a memória ou simplesmente do que seja a consciência de si. Concepções estas que em nada se aproximam da concepção teleológica que sustentava as narrativas de formação da modernidade.

Depois desse pequeno percurso, podemos agora retomar nosso pequeno problema inicial: o senso comum que confunde o autobiográfico com certo narcisismo e necessidade terapêutica. As narrativas de formação, como vimos, trazem em sua origem e deixam como legado o sentido de uma vida que se transforma a partir de uma experiência de superação e que pode ser decomposta nas partes que contribuíram para esse fim. Disso ao sentido de exemplaridade é um passo muito curto e, mais curto ainda, em direção a esse vínculo com um certo caráter "terapêutico", já que uma autobiografia seria algo como eu relato aquilo pelo que passei para me tornar alguém melhor.

Tal associação se deve também ao fato do gesto autobiográfico recair, muitas vezes, sobre os momentos de exceção, ou seja, experiências extremas da vida de um indivíduo que se convertem em matéria artística. As experiências de traumas parecem ser as mais significativas entre as "exceções." Perdas, violências extremas, moléstias, são revisitadas, recriadas nessas elaborações e corroboram para essa associação do autobiográfico com o terapêutico. Da performance Rumstick Road (1967) na qual Spalding Gray retoma o 
suicídio da mãe, aos textos do escritor George Pérec, nos quais ele visita incansavelmente o tema do desaparecimento da família nos campos de concentração nazistas, temos inúmeros exemplos de obras autobiográficas que são marcadas por traumas.

No teatro, podemos citar o espetáculo Luis Antônio-Gabriela, no qual o diretor Nelson Baskerville retoma a vivência de abusos sofridos na infância e a história do irmão que se tornou travesti. Optando pelo registro épico, o espetáculo em suas escolhas formais procura distanciar-se do fato pessoal, ao mesmo tempo que, numa corrente inversa, frisa o caráter de acerto de contas com o passado. É marcante a cena final, na qual depois de uma canção de claro apelo emocional entoada pelos atores, um painel eletrônico deixa correr com letras luminosas o pedido de desculpas de Baskerville para o irmão já falecido.

O espetáculo Azirilhante de Flávia Melmam, ao tratar do delicado tema do suicídio da mãe da criadora do trabalho, opta também por imprimir certa distância em relação ao vivido através de marcados contornos fabulares da dramaturgia e encenação. Diferentemente de Baskerville, que coloca documentos e entrevistas em cena, evidenciando o caráter autobiográfico do trabalho, Melman e a diretora Daniela Duarte não recorrem a nenhum elemento que faça menção explícita ao fato de se tratar de uma história real. O público pode talvez intuir o teor autobiográfico quando em alguns momentos a atriz se dirige diretamente para a plateia e divide algumas reflexões que apontam para a instância da atriz e filha. Mas, mesmo nesses momentos, não há nenhuma explicitação do fato que motivou a criação e processo de quase três anos do espetáculo. É na sinopse divulgada do trabalho, um elemento exterior à dramaturgia e encenação, que o direcionamento para a fruição de uma história de teor autobiográfico se evidencia. Pode-se pensar, em termos de recepção, se a experiência do espetáculo é alterada para o público que lê a obra a partir de uma perspectiva autobiográfica e para aquele que a frui dentro de uma percepção inteiramente fabular. O pesquisador Luiz Fernando Ramos em sua crítica ao espetáculo faz sua leitura a partir da premissa pessoal de uma atriz que decide reabrir as feridas de uma experiência traumática e fazer desta uma obra de arte. $\mathrm{O}$ crítico evidencia a "coragem artística de trazer à tona traumas vividos" nossa problemática da função "terapêutica" que esses processos podem comportar,

7 RAMOS, Luiz Fernando. "Peça usa metáfora para tratar do suicídio". Folha de São Paulo: São Paulo, 2013. http://www1.folha.uol.com.br/fsp/ilustrada/113179-peca-usa-metaforas-para-tratar-do-suicidio.shtml. Consultado em 29 de agosto de 2013. 
Ramos parece concordar com essa hipótese e termina sua apreciação dizendo que a artista "alcançou ali um brilho que a liberta de sua sombra"8.

A possibilidade de superação de algo que se apresenta traumático na esfera pessoal também aparece em alguns dos monólogos do espetáculo Ficção, da Cia Hiato, com direção de Leonardo Moreira. O espetáculo é composto de seis solos nos quais os atores, apresentando-se em seus próprios nomes, relatam experiências aparentemente pessoais (já que em muitos momentos chama-se atenção para a possibilidade do ator estar jogando com essa expectativa do público). No solo executado pelo ator Tiago Amaral conhecemos a história da recusa de um pai em aceitar um filho homossexual. Tiago conta que foi, inclusive, interditado juridicamente pelo pai que queria tirar do filho os direitos de herança não o reconhecendo mais como tal. A narrativa se dá todo o tempo sob a presença de um senhor de idade que acompanha a cena, interage com ela em alguns momentos e, ao longo do espetáculo, ficamos sabendo que se trata do pai de Tiago. Pai e filho em cena, após conhecermos a narrativa da fase certamente conturbada da relação, apontam para a possibilidade de solução do impasse e amadurecimento afetivo do vínculo de ambos. O espetáculo atualiza assim um tema caro ao modelo biográfico da Bildung, que é a trajetória de superação e a qualidade exemplar da experiência. Sem entrar no mérito da atuação e qualidades dramatúrgicas do trabalho, podemos acreditar que parte da fruição e empatia da plateia pelo espetáculo se dá por essas características que destacamos.

Retomando a discussão proposta, o que nos parece é que nessas obras e nas demais tentativas de representação autobiográfica, essas figurações não são simplesmente uma forma de expressar o vivido, mas são o próprio espaço de sua elaboração. Daí seu caráter "terapêutico" se entendermos o terapêutico como o terreno de uma ação sobre si mesmo, sobre o vivido, em que o indivíduo, ao dar forma à experiência, pode entrar em confronto com essas figuras de si mesmo, figuras do passado e do presente, e dar-Ihes mobilidade, dar-Ihes movimento. Por outro lado, essa associação com o terapêutico, que se justifica na própria ideia de Gestalt, compreendida neste dar forma ao vivido, não parece em nada dar conta desse salto representacional que podemos assinalar, sobretudo a partir dos anos 1970 e que marca a arte contem-

8 RAMOS, Luiz Fernando. "Peça usa metáfora para tratar do suicídio". Folha de São Paulo: São Paulo, 2013. http://www1.folha.uol.com.br/fsp/ilustrada/113179-peca-usa-metaforas-para-tratar-do-suicidio.shtml. Consultado em 29 de agosto de 2013. 
porânea. A literatura, as artes plásticas e a performance, com exemplos muito mais frequentes de obras declaradamente autobiográficas, mostram que a figuração nas artes pode se distanciar do modelo da Bildung da modernidade. Já sem nenhuma ilusão de unidade e nenhuma ambição de exemplaridade, o que vemos são obras que não procuram expressar a "expansão" ou "desenvolvimento" do ser em direção à sua harmonia (ou cura?). Ao contrário, elas se fazem nos centros nevrálgicos de nossas representações multifacetadas e instáveis, assim como enfrentam os traumas, não para extrair daí exemplos que possam ser passados adiante, mas para encontrar núcleos da experiência humana que se convertam em imagens potentes de nossa existência política e subjetiva na contemporaneidade.

Talvez seja interessante pensar, a partir da recente profusão de obras autobiográficas na cena teatral contemporânea, de que modo elas estão problematizando tais questões.

Pode-se dizer que hoje um artista que se debruce sobre material autobiográfico tem diante de si este duplo desafio: questionar os modelos representacionais ainda fortemente ligados a essa teleologia da Bildung e, ao mesmo tempo, encontrar na experiência de uma criação autobiográfica o espaço de sua própria reelaboração abrindo possibilidades para verdadeiros saltos de "experienciação" e simbolização do self.

\section{Referências bibliográficas}

ARFUCH, Leonor. O espaço biográfico. Dilemas da subjetividade contemporânea. Rio de Janeiro: EdUERJ, 2010.

DELORY-MOMBERGER, Christine. Filiações e rupturas do modelo autobiográfico na pósmodernidade. In. GALLE, Helmut e outros (Org.). Em primeira pessoa: abordagens de uma teoria da autobiografia. São Paulo: Annablume; Fapesp; FFLCH, USP, 2009.

LEJEUNE, Philippe. Le pacte autobiografique. Paris: Seuil, 1996.

Signes de vie. Le pacte autobiographique 2. Paris: Seuil, 1996.

RICOEUR, Paul. A memória, a história, o esquecimento. Campinas, SP: Editora da Unicamp, 2007.

SAFATLE, Vladmir. Lacan/Vladmir Safatle. 2a ed. - São paulo: Publifolha, 2009.

SAFRA, Gilberto. A face estética do self: teoria e clínica. Aparecida, SP: ideias e letras: São Pailo: Unimarco Editora, 2005.

A po-ética na clínica contemporânea. Aparecida, SP: ideias e letras: São Paulo: Unimarco Editora, 2004.

SARLO, Beatriz. Tempo Passado: cultura da memória e guinada subjetiva. Trad. Rosa Freire d'Aguiar. São Paulo: Companhia das Letras; Belo Horizonte: UFMG, 2007. 